\title{
A fat mass and obesity-associated gene polymorphism influences fat mass in exercise-trained individuals
}

\author{
Jose Antonio ${ }^{1 *} \mathbb{D}$, Sarah Knafo ${ }^{2}$, Ritishka Kapoor ${ }^{2}$ and Jaime L. Tartar $^{2}$
}

\begin{abstract}
Background: A single nucleotide polymorphism (SNP) in the fat mass and obesity-associated (FTO) gene is a strong predictor of obesity in humans. The FTO SNP (rs1421085) results in a T to C nucleotide substitution that may result in an increased risk for obesity in individuals who carry at least one $C$ allele. The purpose of this investigation was to characterize the FTO genotype in a cohort of exercise-trained men and women.

Methods: We tested 108 exercise-trained individuals that included professional mixed martial arts fighters, competitive distance runners, collegiate swimmers, stand-up paddlers as well as a cohort of recreational bodybuilders. Body composition was assessed via dual-energy $x$-ray absorptiometry (DXA). Saliva samples were collected in order to genotype participants and quantify cortisol levels.

Results: The physical characteristics of the subjects were as follows (mean \pm SD): body weight $74.5 \pm 15.6 \mathrm{~kg}$; height 171. $5 \pm 9.5 \mathrm{~cm}$; bone mineral content $2.8 \pm 0.7 \mathrm{~kg}$; fat mass $15.7 \pm 5.5 \mathrm{~kg}$; lean body mass $55.9 \pm 14.4 \mathrm{~kg}$; \% body fat $21.6 \pm 7.0$. Independent samples t tests showed that $C$ allele carriers $(n=54)$ had significantly higher fat mass $\mathrm{t}(106)=3.13$, $p<0.01$ and body fat percentage $t(106)=2.68, p<0.01$, relative to the $\Pi$ group $(n=54)$ (i.e., fat mass: $C /-17.3 \pm 5.6 \mathrm{~kg}$, $\Pi 14.2 \pm 4.6 \mathrm{~kg}$; body fat percentage: C/- group $23.4 \pm 7.4 \%$, TT group 19.9 \pm 6.2$)$. No other measures of body composition were associated with the FTO genotype (i.e., body mineral density, bone mineral content, or lean body mass). Moreover, cortisol levels were significantly higher in the $\Pi$ group relative to the $\mathrm{C}$ allele carriers $\mathrm{t}(106)=2.37, p=0.02$ (i.e., $\left.\prod 0.35 \pm 0.35 \mu \mathrm{g} / \mathrm{dL}, \mathrm{C} /-0.22 \pm 0.16 \mu \mathrm{g} / \mathrm{dL}\right)$.

Conclusions: Our findings demonstrate a relationship between $C$ allele carriers on the FTO gene and a predisposition to a higher fat mass and body fat percentage. In addition, we found no relationship between cortisol and fat mass. However, due to the cross-sectional nature of this investigation, we cannot infer causality regarding the FTO gene and body composition.
\end{abstract}

Keywords: DXA, FTO, Genotype, Athlete

\section{Background}

There is a powerful genetic influence on fat mass with heritability estimates ranging from 40 to $80 \%$ [1]. In particular, polymorphisms in the fat mass and obesity associated (FTO) gene are related to individual differences in food intake and energy balance [2] and can also influence skeletal muscle phenotype [3]. Multiple single nucleotide polymorphisms (SNPs) occur on the FTO gene that may

\footnotetext{
*Correspondence: ja839@nova.edu

${ }^{1}$ Department of Health and Human Performance, Nova Southeastern

University, 3401 South University Drive, Davie, FL 33328, USA

Full list of author information is available at the end of the article
}

influence adipogenesis and obesity [4-6]. Since the obesity-associated SNPs are on the intron 1 region of the FTO gene, the mechanisms through which they influence body mass are uncertain. However, it has recently been shown in humans that a T-C SNP at position 53,767,042 on the FTO gene (rs1421085) causes an increase in IRX3 and IRX5 protein expression during early adipocyte differentiation in favor of energy-storing/white adipocytes over energy-dissipating/beige adipocytes. The critical downstream effect of this is increased energy conservation in the form of augmented fat storage [7].

(C) The Author(s). 2018 Open Access This article is distributed under the terms of the Creative Commons Attribution 4.0 International License (http://creativecommons.org/licenses/by/4.0/), which permits unrestricted use, distribution, and reproduction in any medium, provided you give appropriate credit to the original author(s) and the source, provide a link to the Creative Commons license, and indicate if changes were made. The Creative Commons Public Domain Dedication waiver (http://creativecommons.org/publicdomain/zero/1.0/) applies to the data made available in this article, unless otherwise stated. 
Previous work has shown that exercise intervention can ameliorate the influence of FTO risky alleles on BMI on the FTO rs8050136 SNP [8, 9] and the rs9939609 SNP [10-12]. However, due to the direct influence of the FTO SNP rs1421085 on early adipocyte differentiation, the effect of exercise training on body fat in the risky allele carriers of the rs1421085 SNP are less certain. The purpose of the study was to examine the relationship between FTO genotype and body composition in trained individuals. We also determined if salivary cortisol is related to fat mass in exercise-trained individuals.

\section{Methods}

\section{Participants}

Study subjects came to the laboratory on a single occasion for body composition assessment and the provision of a saliva sample. In accordance with the Helsinki Declaration, the university's Institutional Review Board approved all procedures the involved human subjects. Written informed consent was obtained prior to participation. All testing took place between 1130 and 1400. Participants were instructed not to exercise or eat or drink anything other than water one hour prior to testing.

\section{Body composition}

One hundred and eight subjects had their height and weight determined using a calibrated scale. Body composition was assessed via dual-energy X-ray absorptiometry (DXA) (Model: Hologic Horizon W; Hologic Inc., Danbury CT USA). Quality control calibration procedures were performed on a spine phantom. Subjects wore typical athletic clothing and removed all metal jewelry. They were positioned supine on the DXA within the borders delineated by the scanning table. Each whole body scan took approximately seven minutes.

\section{Genotyping}

Genomic DNA was extracted in a QIAcube instrument following the manufacturer's standard protocol for saliva nucleic acid extraction (QIAGEN, Valencia, CA). After isolation, allelic discrimination for the FTO gene was determined via real-time polymerase chain reaction (PCR) using a TaqMan SNP genotyping assay using fluorogenic probes (Applied Biosystems, CA) with the primer sequence TAGC AGTTCAGGTCCTAAGGCATGA[C/T]ATTGATTAAG TGTCTGATGAGAATT. Thermal cycling was performed on StepOne Real-Time PCR system (Applied Biosystems, CA). The amplification mix contained the following ingredients: $12.5 \mu \mathrm{L}$ of PCR master mix (QIAGEN, Valencia, CA), $1.25 \mu \mathrm{L}$ of TaqMan 20X working stock, $10.25 \mu \mathrm{L}$ of RNase- and DNase-free water (Sigma), and $1.0 \mu \mathrm{L}$ of sample DNA, in a total volume of $25 \mu \mathrm{L}$ per single tube reaction. The PCR conditions were $95{ }^{\circ} \mathrm{C}$ for $10 \mathrm{~min}$ followed by 40 repeated cycles of $95{ }^{\circ} \mathrm{C}$ for $15 \mathrm{~s}$ and $60{ }^{\circ} \mathrm{C}$ for $60 \mathrm{~s}$. Aliquots corresponding to the products from the first round of amplification were used as templates for a second round of amplification (30 cycles, with the same conditions). Genotypes were determined automatically via the StepOne software (Applied Biosystems, CA) based on the fluorescence signals. Samples were run in duplicate and in the case of a call discrepancy, samples were rerun.

\section{Cortisol}

Saliva samples were run in duplicate and quantified via a human cortisol enzyme immunoassay (EIA) kit per the manufacturer's instructions (Salimetrics LLC, USA). The samples were immediately read in a BioTek ELx800 plate reader (BioTek Instruments, Inc., USA) at $450 \mathrm{~nm}$ with a correction at $630 \mathrm{~nm}$. All samples were within the detection ranges indicated in the immunoassay kits. The variation of sample readings was within the expected limits and the average intra-assay coefficient of variation was $4.76 \%$. Final concentrations for the biomarkers were generated by interpolation from the standard curve in $\mu \mathrm{g} / \mathrm{dL}$.

\section{Statistical analysis}

We conducted a series of independent samples t-tests to assess the relationship between FTO genotype and DXA body composition measures. An independent samples t-test test was also run to determine a possible relationship between FTO genotype and cortisol levels. Significant findings were followed up with $2 \times 2$ ANOVAs in order to test for possible sex $\mathrm{x}$ genotype interactions. The distribution of allele frequencies was determined by the Hardy-Weinberg Exact (HWE) test; moreover, the association of allele status was analyzed using the chi-square test. All calculations were conducted using an SPSS statistical package (version 19, SPSS Inc., IBM). All reported $p$-values are two-tailed with a priori significance level of $p<0.05$.

\section{Results}

The physical characteristics of the subjects were as follows (mean $\pm \mathrm{SD}$ ): body weight $74.5 \pm 15.6 \mathrm{~kg}$; bone mineral content $2.8 \pm 0.7 \mathrm{~kg}$; fat mass $15.7 \pm 5.5 \mathrm{~kg}$; lean body mass $55.9 \pm 14.4 \mathrm{~kg}$; body fat percentage $21.6 \pm 7.0 \%$. The population that we studied consisted of the following: 41 resistance-trained individuals (primarily recreational bodybuilders), 22 competitive stand-up paddlers/rowers, 15 professional fighters (i.e., MMA, boxing), 11 collegiate division II swimmers, 9 collegiate division II track and field athletes, 8 collegiate division II distance runners, 1 division II collegiate soccer player and 1 distance cyclist. Thus, 42 and 66 subjects primarily performed aerobic and anaerobic exercise, respectively. The percentage of the TT and C/- 
carriers that were aerobic athletes was $40 \%$ and $42 \%$, respectively. Thus, no differences existed regarding the distribution of athlete type (aerobic versus anaerobic).

\section{Genotype frequency}

FTO genotype frequencies were as follows: $14 \% \mathrm{CC}$, $37 \%$ AG, and $49 \%$ GG. The HWE test showed that $\chi^{2}=$ 2.73, $p>0.05$, suggesting that the population is consistent with Hardy-Weinberg Equilibrium, and confirming that the allele types were randomly sampled. Because previous research suggests carrying one $C$ allele in rs1421085 associates with an obesity risk $[13,14]$, we collapsed across genotypes containing the $\mathrm{C}$ allele. The $\mathrm{CC}$ homozygotes and the CT heterozygotes ( $n=54,25$ males) were compared to the TT homozygotes ( $\mathrm{n}=54,31$ males).

\section{Association between FTO and body composition measures}

There was no significant difference in body weight between the $\mathrm{C} /-$ and TT groups (mean $\pm \mathrm{SD}: \mathrm{C} /-75.3 \pm 17.1 \mathrm{~kg}$ and TT $70.7 \pm 12.2 \mathrm{~kg}$ ). The role of the FTO genotype on body composition is provided in Figs. 1, 2, 3, 4 and 5. The FTO allele associated with obesity was significantly higher on two measures of body fat. Specifically, fat mass was significantly greater $\mathrm{t}(106)=3.13, p=0.002$ in the $\mathrm{C} / \mathrm{-}$ group $(17.3 \pm 5.6 \mathrm{~kg})$ relative to the TT group $(14.2 \pm 4.6 \mathrm{~kg})$ (Fig. 1). Body fat percentage was significantly greater $\mathrm{t}(106)=2.68$, $p=0.009$ in the $\mathrm{C} /-$ group $(23.4 \pm 7.4 \%)$ relative to the TT group (19.9 \pm 6.25$)$ (Fig. 2). There were no between group differences for lean body mass, bone mineral content, and bone mineral density (Figs. 3, 4 and 5). We also ran a follow up 2 X 2 analysis of variance to probe for sex by genotype effects. This test showed no significant sex $\mathrm{X}$ genotype interaction for body fat percentage $F(1,104)=0$, $p=0.99)$ or total fat mass $\mathrm{F}(1,104=3.18, p=0.08)$. Results for cortisol revealed that the TT group had significantly

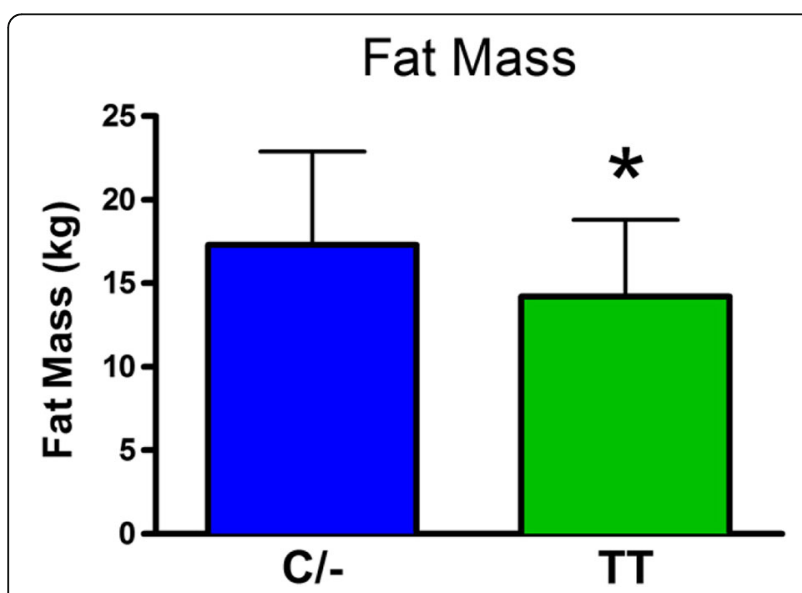

Fig. 1 The relationship between fat mass and genotype. Fat mass was significantly lower in the $\Pi$ group $(p=0.002)$. (Mean \pm SD)

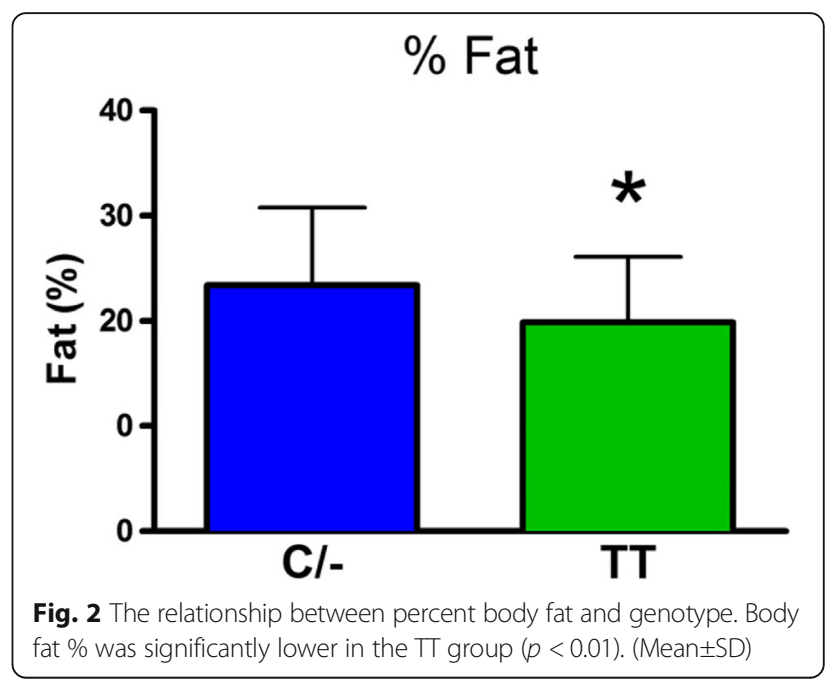

higher $\mathrm{t}(106)=2.36, p=0.02$ cortisol $(0.35 \pm 0.35 \mu \mathrm{g} / \mathrm{dL})$ relative to the $\mathrm{C} /-$ group $(0.22 \pm 0.16 \mu \mathrm{g} / \mathrm{dL})$ (Fig. 6).

\section{Discussion}

The current investigation found that $\mathrm{C}$ allele carriers had significantly higher fat mass and a body fat percentage relative to the TT group. Thus, even in a group of highly trained individuals, the risk allele was associated with higher body fat. One could speculate that in spite of intense exercise training, $C$ allele carriers may still have greater fat mass than TT individuals. One might suggest that those who perform primarily endurance activities tend to carry less fat (i.e., fat mass and percent body fat). However, that was not the case in our investigation. We had an equal percentage of athletes that performed aerobic or anaerobic activities in the $\mathrm{C} /-$ and TT groups.

There is a dearth of studies on the FTO gene as it relates to an athletic or exercise-trained population. Eynon

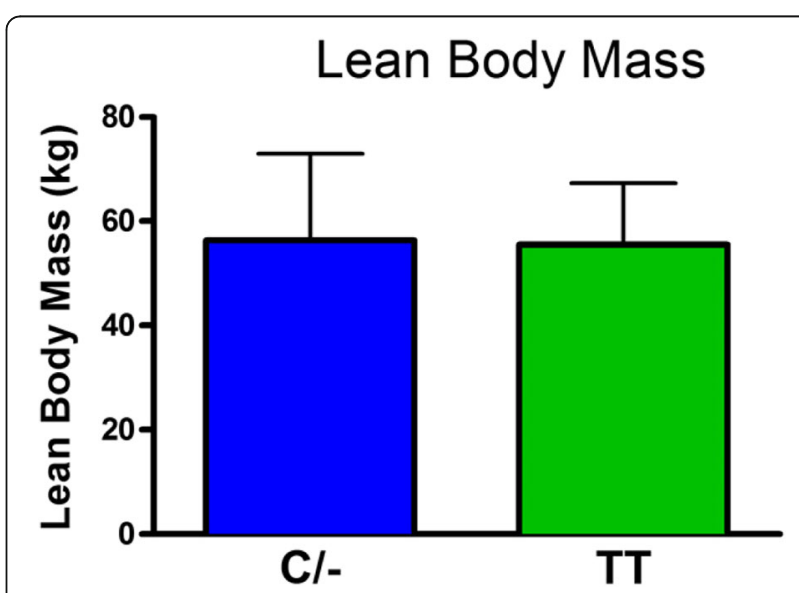

Fig. 3 The relationship between lean body mass and genotype. There were no significant differences in lean body mass. (Mean \pm SD) 


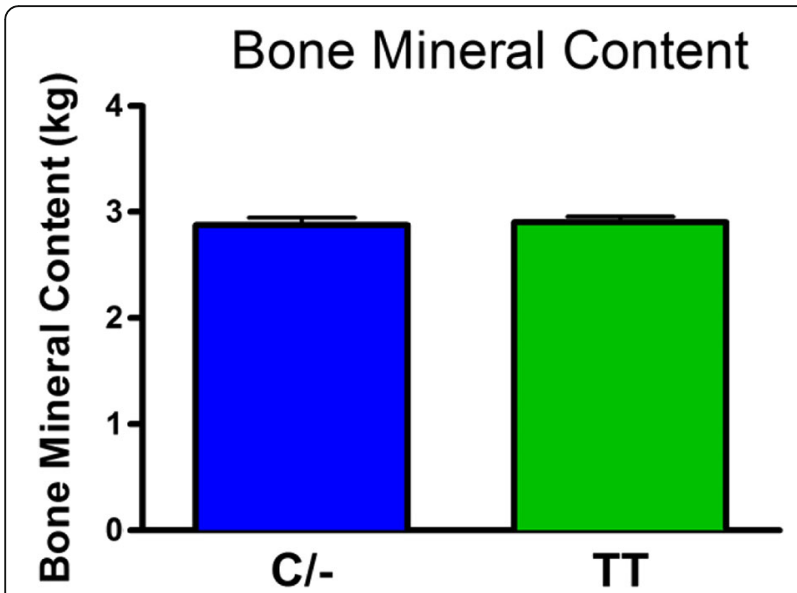

Fig. 4 The relationship between bone mineral content and genotype There were no significant differences in bone mineral content. (Mean \pm SD)

et al. found that the FTO A/T polymorphism was not associated with elite athletic status in a large cohort of European athletes (i.e., 266 endurance and 285 sprint/ power athletes) [15]. Certainly this makes sense inasmuch as athletic performance, particularly in skill sports, cannot be predicted solely on the basis of body composition. Huuskonen et al. studied 846 healthy Finnish males and found that aerobic fitness does not modify the effect of FTO rs1421085 variation on body composition traits [16]. This is in agreement with our data showing that the percentage of endurance-trained individuals was equally represented in the TT and C/- genotypes. Heffernan et al. genotyped a group of non-athletes and elite rugby players for the FTO gene [17]. They discovered that $\mathrm{T}$ allele carriers had greater total body and total appendicular lean mass versus the AA genotype. Furthermore, the $\mathrm{T}$ allele was more common (94\%) in selected elite rugby union athletes. Thus, at least in comparing

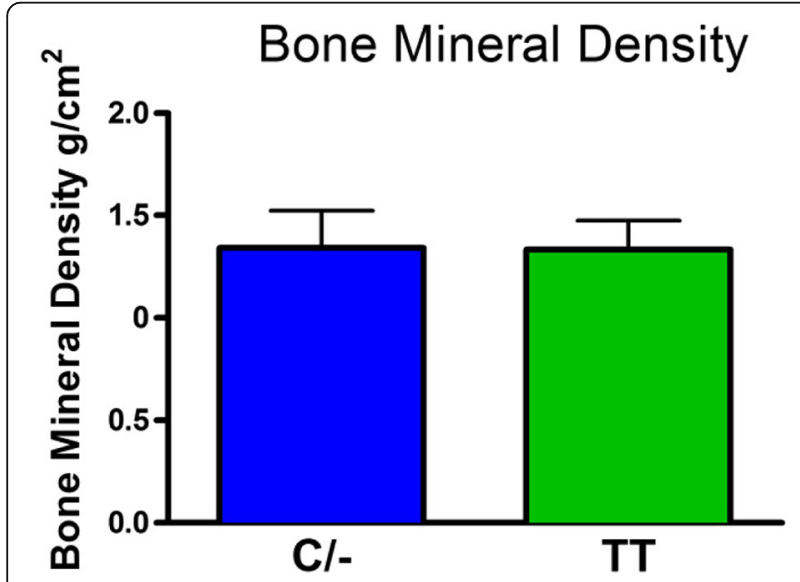

Fig. 5 The relationship between bone mineral density and genotype. There were no significant differences in bone mineral density. (Mean \pm SD)

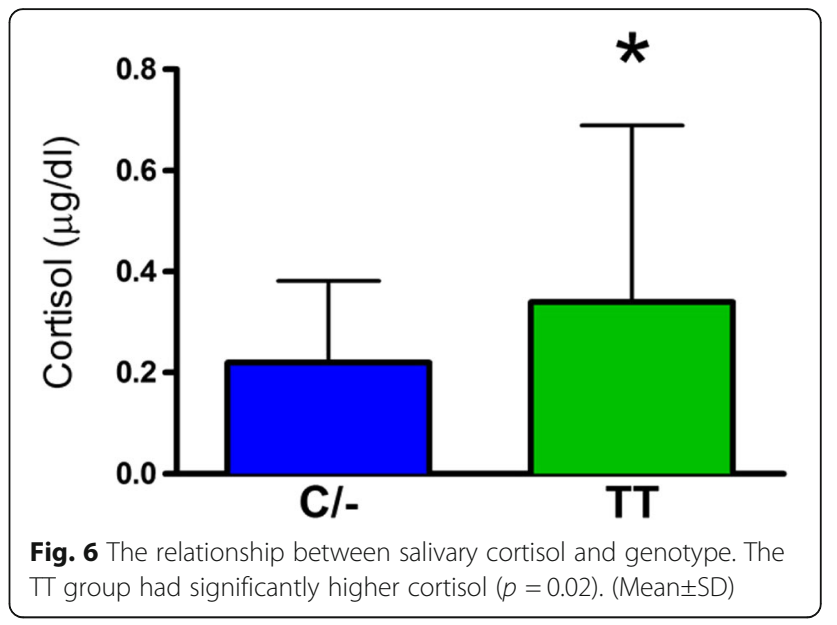

athletes to non-athletes, the TT genotype is ostensibly more common.

A further aim of the study was to show whether cortisol is a pathway through which $\mathrm{C}$ allele carriers have greater levels of body fat. This possibility has arisen, at least in part, because previous work has shown that exercise increases cortisol levels [18] and there exists an association between high cortisol levels and obesity [19]. Interestingly, we found that the TT FTO rs1421085 group had significantly higher cortisol levels than the risky C/- group. Given that the TT group had significantly lower body fat percentage and fat mass than the $\mathrm{C}$-group, this finding supports that notion that cortisol is not related to increased fat mass in exercise-trained individuals. Although it is unclear why the TT genotype relates to higher cortisol levels, one might speculate that the TT group has a greater ratio of brown to white adipose tissue than the $\mathrm{C} /-$ group. This could result in higher cortisol levels due to the increased energy need in the form of increased calorie expenditure [7]. In support of this idea, a previous study found that higher cortisol levels were associated with increased activity in brown adipose tissue [20]. However, while this idea is intriguing, more work will need to be done to clarify the relationship between FTO rs1421085 genotype, brown vs. white adipose tissue, and cortisol.

A major limitation of our investigation is the crosssectional design. For instance, it would be intriguing to see if exercise-trained individuals that are TT can lose more fat mass than their $\mathrm{C} /$ - counterparts when given the same hypocaloric diet. Based on the cross-sectional data from our investigation, one would predict that TT individuals should lose more fat mass, similar to a previous study that investigated a different FTO SNP [21] since the common FTO polymorphisms all associate with obesity and there is high linkage disequilibrium between them [22, 23]. In particular, Zhang et al. tested the effect of FTO variant on weight loss in response to 
2-year diet interventions in 742 obese adults [21]. They discovered that carriers of the risk allele of the FTO variant rs1558902 had a greater reduction in weight, body composition, and fat distribution in response to a high-protein diet. Thus, at least in this cohort of obese individuals, a high protein diet may indeed be optimal choice as it relates to changes in body composition. Whether such a strategy would work for an exercisetrained population that has a low body fat percentage is unknown. Future work is needed to elucidate the role of protein intake on modifying body composition in exercise-trained individuals.

\section{Conclusion}

In summary, the cross-sectional data from this investigation suggest that in spite of intense athletic training, C allele carriers (FTO gene, rs1421085) tend to have a greater percentage of fat mass; however, it should be noted that the $\mathrm{C} /-$ group in our investigation still have quite low body fat percentages. Thus, it is clear that exercise training can dramatically modify one's phenotype despite a purported genetic limitation.

\section{Abbreviations}

DXA: Dual energy x-ray absorptiometry; EIA: Enzyme immunoassay; FTO gene: Fat mass and obesity associated gene; Kg: Kilogram; MMA: Mixed martial arts; Nucleotides A, T, C, G stand for: Adenine, thymine, cytosine guanine; SNP: single nucleotide polymorphism

\section{Availability of data and materials}

Please contact author for data requests.

\section{Author's contributions}

JA, JT, SK and RK performed the data collection. JT performed the statistical analysis. All authors helped with the draft of the manuscript, read and approved the final paper.

\section{Ethics approval and consent to participate}

The study was conducted in accordance with the requirements of the declarations of Helsinki. All participants were informed about the procedures and signed an informed consent form prior to enrollment in the study.

\section{Consent for publication}

Not applicable

\section{Competing interests}

The authors declare that they have no competing interests.

\section{Publisher's Note}

Springer Nature remains neutral with regard to jurisdictional claims in published maps and institutional affiliations.

\section{Author details}

'Department of Health and Human Performance, Nova Southeastern University, 3401 South University Drive, Davie, FL 33328, USA. ${ }^{2}$ Department of Psychology and Neuroscience, Nova Southeastern University, Davie, FL, USA.

Received: 26 April 2018 Accepted: 1 August 2018

Published online: 08 August 2018

\section{References}

1. Speliotes EK, et al. Association analyses of 249,796 individuals reveal 18 new loci associated with body mass index. Nat Genet. 2010;42(11):937-48.
2. Han Z, et al. Crystal structure of the FTO protein reveals basis for its substrate specificity. Nature. 2010;464(7292):1205-9.

3. Sonestedt E, Gullberg B, Ericson U, Wirfält E, Hedblad B, Orho-Melander M. Association between fat intake, physical activity and mortality depending on genetic variation in FTO. Int J Obesity. 2011;35(8):1041-49. https://doi. org/10.1038/ijo.2010.263.

4. Frayling TM, et al. A common variant in the FTO gene is associated with body mass index and predisposes to childhood and adult obesity. Science. 2007;316(5826):889-94.

5. Dina C, et al. Variation in FTO contributes to childhood obesity and severe adult obesity. Nat Genet. 2007:39(6):724-6.

6. Andreasen $\mathrm{CH}$, et al. Low physical activity accentuates the effect of the FTO rs9939609 polymorphism on body fat accumulation. Diabetes. 2008;57(1):95-101.

7. Claussnitzer M, et al. FTO obesity variant circuitry and adipocyte Browning in humans. N Engl J Med. 2015:373(10):895-907.

8. Mitchell JA, et al. FTO genotype and the weight loss benefits of moderate intensity exercise. Obesity (Silver Spring). 2010;18(3):641-3.

9. Sailer $C$, et al. FTO genotype interacts with improvement in aerobic fitness on body weight loss during lifestyle intervention. Obes Facts. 2016;9(3):174-81.

10. Moraes GG, et al. Genotypic carriers of the obesity-associated FTO polymorphism exhibit different cardiometabolic profiles after an intervention. An Acad Bras Cienc. 2016:88(4):2331-9.

11. Livingstone KM, et al. FTO genotype and weight loss: systematic review and meta-analysis of 9563 individual participant data from eight randomised controlled trials. Bmj. 2016;354:14707.

12. Xiang $\mathrm{L}$, et al. FTO genotype and weight loss in diet and lifestyle interventions: a systematic review and meta-analysis. Am J Clin Nutr. 2016;103(4):1162-70.

13. Wang L, et al. Variant rs 1421085 in the FTO gene contribute childhood obesity in Chinese children aged 3-6 years. Obesity research \& clinical practice. 2013;7(1):e14-22.

14. Reddon $\mathrm{H}$, et al. Physical activity and genetic predisposition to obesity in a multiethnic longitudinal study. Sci Rep. 2016;6:18672.

15. Eynon $\mathrm{N}$, et al. The FTO a/T polymorphism and elite athletic performance: a study involving three groups of European athletes. PLoS One. 2013;8(4):e60570.

16. Huuskonen $\mathrm{A}$, et al. Aerobic fitness does not modify the effect of FTO variation on body composition traits. PLoS One. 2012;7(12):e51635.

17. Heffernan SM, et al. Fat mass and obesity associated (FTO) gene influences skeletal muscle phenotypes in non-resistance trained males and elite rugby playing position. BMC Genet. 2017;18(1):4.

18. Chen C, et al. The exercise-glucocorticoid paradox: how exercise is beneficial to cognition, mood, and the brain while increasing glucocorticoid levels. Front Neuroendocrinol. 2017:44:83-102

19. Hewagalamulage SD, et al. Stress, cortisol, and obesity: a role for cortisol responsiveness in identifying individuals prone to obesity. Domest Anim Endocrinol. 2016;56(Suppl):S112-20.

20. Robinson $\sqcup$, et al. Brown adipose tissue activation as measured by infrared thermography by mild anticipatory psychological stress in lean healthy females. Exp Physiol. 2016;101(4):549-57.

21. Zhang X, et al. FTO genotype and 2-year change in body composition and fat distribution in response to weight-loss diets: the POUNDS LOST trial. Diabetes. 2012;61(11):3005-11.

22. Scuteri A, et al. Genome-wide association scan shows genetic variants in the FTO gene are associated with obesity-related traits. PLoS Genet. 2007:3(7):e115.

23. Villalobos-Comparan M, et al. The FTO gene is associated with adulthood obesity in the Mexican population. Obesity (Silver Spring). 2008;16(10):2296-301.

Ready to submit your research? Choose BMC and benefit from:

- fast, convenient online submission

- thorough peer review by experienced researchers in your field

- rapid publication on acceptance

- support for research data, including large and complex data types

- gold Open Access which fosters wider collaboration and increased citations

- maximum visibility for your research: over $100 \mathrm{M}$ website views per year

At $\mathrm{BMC}$, research is always in progress.

Learn more biomedcentral.com/submission 